\title{
Increased Levels of Nitric Oxide, Cortisol and Adrenomedullin in Patients with Chronic Schizophrenia
}

\author{
Necat Yılmaz ${ }^{\mathrm{a}}$ Hasan Herken $^{\mathrm{b}}$ Hülya Kanbur Cicek ${ }^{\mathrm{a}}$ Ahmet Celik $^{\mathrm{a}}$

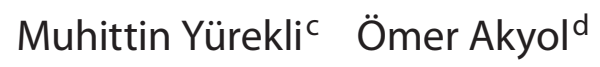

Departments of a Biochemistry and Clinical Biochemistry and b Psychiatric Disorders, Faculty of Medicine, University of Gaziantep, Gaziantep, 'Department of Molecular Biology, Faculty of Science and Art,

University of Inonu, Malatya, and d Department of Biochemistry and Clinical Biochemistry, Faculty of Medicine,

University of Hacettepe, Ankara, Turkey

\section{Key Words}

Schizophrenia $\cdot$ Cortisol $\cdot$ Adrenomedullin $\cdot$ Nitric oxide •

Dehydroepiandrosterone sulfate

\begin{abstract}
Objective: To investigate the levels of serum cortisol, dehydroepiandrosterone sulfate (DHEA-S), nitric oxide (NO) and adrenomedullin (AM) in schizophrenic patients. Subjects and Methods: Sixty-six male patients with chronic schizophrenia and 28 normal male subjects participated in this study. The duration of disease was $145 \pm 120$ (mean \pm SD) months. Serum levels of cortisol and DHEA-S were measured by electrochemiluminescence; plasma nitrite levels as an index of NO were measured with the Griess reaction, while plasma AM concentration was measured by using high-performance liquid chromatography. Results: Patients (12.48 \pm $3.2 \mu \mathrm{g} / \mathrm{dl})$, as compared to controls (10.31 $\pm 3.1 \mu \mathrm{g} / \mathrm{dl})$, had higher levels of baseline cortisol $(p<0.05)$. DHEA-S levels were lower in patients though this did not reach statistical significance (302 $\pm 156 \mu \mathrm{g} / \mathrm{dl}$ compared to control, $322 \pm$ $96 \mu \mathrm{g} / \mathrm{dl}, \mathrm{p}>0.05)$. The mean levels of plasma AM and NO in the schizophrenic group $(44.33 \pm 5.07 \mathrm{pmol} / \mathrm{l}$ and $36.27 \pm$ $17.6 \mu \mathrm{mol} / \mathrm{l})$ were significantly higher than the levels in the control group (14.56 $\pm 4.03 \mathrm{pmol} / \mathrm{l}$ and $32.54 \pm 7.14 \mu \mathrm{mol} / \mathrm{l}$;
\end{abstract}

\section{KARGER}

Fax +4161306 1234

E-Mail karger@karger.ch

www.karger.com (c) 2007 S. Karger AG, Basel

1011-7571/07/0162-0137\$23.50/0

Accessible online at:

www.karger.com/mpp $p<0.001, p<0.03$, respectively). There was a positive association between duration of disease and cortisol/DHEA-S ratio and cortisol level. Conclusion: The data show that schizophrenia is associated with abnormal levels of cortisol, DHEA-S, NO and AM.

Copyright $\odot 2007$ S. Karger AG, Basel

\section{Introduction}

Both clinical and biological data indicate that schizophrenic patients have impaired biological response to stress [1]. Despite evidence of elevated cortisol levels in schizophrenia, no well-replicated findings have emerged. More recently, research has been conducted on neurohormonal indicators of stress responsivity, particularly cortisol release resulting from activation of the hypothalamic-pituitary-adrenal (HPA) system [1]. Both the behavioral and biological data indicate that stress worsens schizophrenic symptoms and that the disorder is associated with a heightened response to stressors [1]. A neural mechanism for these phenomena is suggested by the augmenting effect of the HPA system on dopamine synthesis and receptors. Assuming that the diathesis for schizophrenia involves an abnormality in dopamine receptors, 
it is proposed that the HPA axis acts to potentiate schizophrenic systems by means of its effects on dopamine. Dehydroepiandrosterone (DHEA) and its conjugate ester, dehydroepiandrosterone sulfate (DHEA-S), are abundant steroids in the circulation [2]. Brain DHEA(-S) levels exceed their respective concentrations in plasma. Only recently have they been recognized as neuroactive steroids and in fact, in the brain they interact with membrane receptors, such as $\mathrm{N}$-methyl-D-aspartate and $\gamma$ aminobutyric acid receptors, and with the genomic androgen receptor [2]. Moreover, the brain is not only the target tissue for neuroactive steroids, but may itself produce them de novo from cholesterol in glia cells and in neurons. Although most of the biochemical pathways involved in the synthesis of neurosteroids in the brain and periphery have been identified, the mechanisms that regulate the activity of the neurosteroid-producing cells are still largely unknown $[1,2]$.

Basic and clinical studies are ongoing to assess the role of DHEA in normal physiological aging, as well as in various pathophysiological states (e.g. atherosclerosis, rheumatoid arthritis, osteoporosis, adrenal insufficiency, polycystic ovarian syndrome and schizophrenia) [2]. Low levels of DHEA are also associated with Alzheimer's disease, multi-infarct dementia and anxiety [2-5]. While many reports have demonstrated the effects of DHEA on neural, endocrine, immune and metabolic systems, the relevance of this neuroactive steroid to psychiatric disorders is still not well known.

Recently, research has focused on the biochemical and molecular actions of nitric oxide (NO) in normal conditions as well as its potential alteration in pathological conditions like schizophrenia [6, 7]. Evidence is accumulating for a possible role of NO in schizophrenia. The formation of $\mathrm{NO}$ is catalyzed by the enzyme nitric oxide synthase (NOS) that is present in a variety of cell types. NO can also be considered an atypical neurotransmitter in the nervous system and therefore it seems more appropriate to describe it as a second messenger or hormone. NO is a soluble gas produced by the activity of an enzyme found in neurons [6]. It has been implicated in a great number of normal physiological functions, such as noradrenaline and dopamine release, memory and learning, regulation of the cerebrovascular system, modulation of wakefulness and nociception, olfaction, food intake, and drinking, as well as pathologies such as Alzheimer's, Huntington's disease, cerebral ischemia and stroke [6].

Adrenomedullin (AM), a recently discovered 52-amino acid peptide hormone, has biological actions on various organs, most of which appear to be involved in the regulation of cardiovascular function and body fluid electrolyte homeostasis. This peptide may also be important both as a paracrine and autocrine factor, and may serve as a classical circulating hormone. Human AM mRNA was observed in pheochromocytoma, adrenal medulla, heart ventricle, kidney, lung, pancreas, and brain. AM induces vasorelaxation by activating adenylate cyclase and also by stimulating the release of NO. On the other hand, AM, which is also a neurotransmitter, possesses an immune function in the brain; $\mathrm{NO}$ and $\mathrm{AM}$ also function in the regulation of the HPA system [7].

The aim of this study was, first, to compare the levels of serum cortisol, DHEA-S, NO and AM in schizophrenic patients with those of normal subjects, and, second, to determine the degree of correlation between the levels of these chemicals and the levels of psychopathology/distress in these patients.

\section{Subjects and Methods}

\section{Subjects}

Sixty-six male patients (mean age $=33.6 \pm 11$ years) with schizophrenia and 28 normal male subjects (mean age $=34.4 \pm$ 12 years) participated in this study. The patients were enrolled from the Psychiatric Clinic, University of Gaziantep Hospital, Gaziantep, Turkey. The study was approved by the local ethics committee. The Psychiatric Ethics Committee, Gaziantep University Hospital approved the study. A complete description of the study was given to each patient, patient's relatives and the hospital authority and to control subjects. All patients were taking stable doses of one of the neuroleptics (haloperidol, chlorpromazine, thioridazine, fluphenazine, zuclopenthixole). The treatment protocol of patients with relatively low or high doses of antipsychotics, expressed in chlorpromazine equivalents, was investigated in order to see the effects of low ( $<400 \mathrm{mg} /$ day) or high (>400 mg/ day) doses of neuroleptics on total nitrite and AM levels. A DSMIV diagnosis of chronic schizophrenia was established on the basis of independent clinical interviews and review of the patient records by 2 psychiatrists using the Brief Psychiatric Rating Scale (BPRS), The Scale for the Assessment of Negative Symptoms (SANS) and The Scale for the Assessment of Positive Symptoms (SAPS) [8]. Patients and controls with a history of chronic systemic diseases such as diabetes mellitus, hypertension, severe head injury or seizure and inflammatory disease were excluded from the study. Inclusion criteria were: age between 18 and 55 years, no major medical or neurological illness, no previous or present additional psychiatric disorders or substance abuse disorder. Among individuals with schizophrenia, subjects with $(n=5)$ and without $(\mathrm{n}=61)$ a lifetime history of suicide attempt were assessed with the Present State Examination. At the assessment point, all patients had been receiving stable oral doses of psychotropic drugs for at least 1 month and were studied during the phase of clinical stabilization (i.e., they were analyzed during the residual period). The absence of medical or neurological illness was verified by means of physical and neurological examination, 
routine laboratory investigation, treating physician report and medical records. Age- and sex-matched individuals without any clearly evident psychiatric illness or substance abuse were recruited as control subjects for the study.

\section{Sample Collection and Storage}

Patients and normal volunteers were controlled for time of awakening, morning activity, caffeine consumption and smoking, factors that can affect morning neurosteroid levels [2]. All participants were instructed to avoid morning exercises. A blood sample of $10 \mathrm{ml}$ was collected between 8.30 and 11.30 a.m. and divided into 3 subsamples for measurement of cortisol and DHEA$\mathrm{S}$, nitrite and AM. Immunoassay (electrochemiluminescence, Roche Elecsys ${ }^{\circledR}$ E170) was used to measure cortisol and DHEA-S. Griess reaction was used to measure plasma nitrite levels. Total nitrite (nitrite + nitrate) was measured after conversion of nitrate to nitrite by copperized cadmium granules by a spectrophotometer at $545 \mathrm{~nm}$ (Ultraspec Plus, Pharmacia LKB Biochrom Ltd., England). A standard curve was established with a set of serial dilutions $\left(10^{-8}-10^{-3} \mathrm{~mol} / \mathrm{l}\right)$ of sodium nitrite. Results were expressed as micromoles per liter of plasma. High-performance liquid chromatography (HPLC) was used to measure AM plasma level. Serum samples were subjected to reverse-phase HPLC (C-18 column, $4.6 \times 250 \mathrm{~mm}$, Cecil 1100, Supelco, UK), with a linear gradient dilution of $\mathrm{CH}_{3} \mathrm{CN}$ from 10 to $60 \%$ in a solution of $0.1 \%$ trifluoroacetic acid. Rat AM (1-50 pmol $/ \mathrm{ml})$ was used as the standard (Phoenix Pharmaceutical Inc., Mountain, Calif., USA).

\section{Statistical Analyses}

MedCalc ${ }^{\circledR}$ (7.0 version) for Windows was used for the statistical analyses of data. Nonparametric statistical analyses were used. The significance of differences between groups were estimated by Mann-Whitney $U$ test and differences were considered significant when $\mathrm{p}<0.05$. Bivariate comparisons were examined using Spearman correlation coefficients $(r)$ and values were corrected for ties. Two-tailed significance values were used. Correlations were run between age, body mass index, urea, creatinine, onset of disease, duration of disease, BPRS total, SANS total, SAPS total, DHEA-S, AM, NO, cortisol/DHEA-S ratio and cortisol levels.

\section{Results}

\section{Subject Characteristics}

Schizophrenic patients and those in the controls were matched for gender, age and smoking. The mean BPRS total score of schizophrenia patients was $17.89 \pm 10.2$ (mean \pm SD). The mean SANS total scores were $56.97 \pm$ 28.19 and SAPS total scores were $35 \pm 30.75$. Duration of disease was $145 \pm 120$ months $(95 \%$ CI for the mean: 114-175) in patients (table 1).

\section{Analyte Levels}

Patients, as compared to controls, had higher levels of baseline cortisol. The DHEA-S levels were lower in patients though this did not reach statistical significance.
Table 1. Characteristic of subjects (mean \pm SD)

Patients $(n=66)$ Controls $(n=28)$

Duration of disease, months $145 \pm 120$

Onset of disease, years $22 \pm 9$

Age, years

Smoking, \%

$33.6 \pm 11$

39

$34.4 \pm 12$

BPRS total score

SANS total scores

SAPS total scores

Male gender, \%

$17.89 \pm 10.2$

$56.97 \pm 28.19$

$35 \pm 30.75$

100

100

Table 2. Analyte levels (mean \pm SD)

\begin{tabular}{lccl}
\hline & Patients $(\mathrm{n}=66)$ & Controls $(\mathrm{n}=28)$ & $\mathrm{p}$ \\
\hline Cortisol, $\mu \mathrm{g} / \mathrm{dl}$ & $12.48 \pm 3.2$ & $10.31 \pm 3.1$ & $<0.05$ \\
DHEA-S, $\mu \mathrm{g} / \mathrm{dl}$ & $302 \pm 156$ & $322 \pm 96$ & $>0.05$ \\
AM, $\mathrm{pmol} / \mathrm{l}$ & $44.33 \pm 5.07$ & $14.56 \pm 4.03$ & $<0.001$ \\
Total nitrite, $\mu \mathrm{mol} / \mathrm{l}$ & $36.27 \pm 17.6$ & $32.54 \pm 7.14$ & $<0.03$ \\
\hline
\end{tabular}

The mean levels of plasma AM and total nitrite in the schizophrenic group were significantly higher than the levels in the control group (table 2).

There was a significant correlation between the duration of disease and cortisol $(\mathrm{r}=0.332, \mathrm{p}<0.01)$, and cortisol/DHEA-S ratio $(r=0.417, \mathrm{p}<0.001)$ in patients. In addition, plasma AM levels were found to be significantly correlated with SAPS total $(\mathrm{r}=0.36, \mathrm{p}=0.005)$. There were no correlations between other analytes.

The intra- and interassay coefficients of variations for cortisol were 3.7 and $11.4 \%$, and for DHEA-S 2.8 and $19.6 \%$, respectively. Analytical sensitivity (lower detection limit) of DHEA-S was $0.003 \mu \mathrm{mol} / \mathrm{l}$ and analytical specificity for DHEA-S; the cross-reactivities were found to be $0.178 \%$.

\section{Discussion}

In the present study, levels of AM and total nitrite were higher in schizophrenic patients than in controls; AM levels of schizophrenic patients were threefold higher than those of controls. Huang et al. [9] suggested that only male schizophrenic patients have higher AM mRNA levels than controls. As accumulating evidence suggests that AM has multiple regulatory roles in the brain, the 
significance of the increased expression of AM in some schizophrenic patients is worthy further study. AM levels significantly correlated with SAPS total. Disorders in the HPA axis, which is also affected in schizophrenia, are often seen in psychiatric patients. NO and AM function in the regulation of the hypothalamo-neurohypophysial system and HPA axis [7]. Several studies have indicated that AM may function as a neurotransmitter, neuromodulator or neurohormone in the brain in addition to its hemodynamic effect on the cardiovascular system. AM has a wide distribution in the brain and may function as a neurotransmitter or neuromodulator. Increased AM mRNA expression in lymphoblastoid cell lines from schizophrenic patients has shown that AM itself, or other genetic factors that regulate the expression of AM, might play a role in the pathogenesis of schizophrenia.

Our study with male schizophrenic patients shows higher levels of cortisol and a trend towards lower DHEA$S$ levels in comparison to normal controls. There was also a positive association between duration of disease and cortisol/DHEA-S ratio and cortisol levels. Stress axis dysfunction may occur in schizophrenia as is indicated by the high levels of corticotropin-releasing hormone within the cerebrospinal fluid, failure to suppress plasma levels of cortisol in response to dexamethasone and overactivity of the pituitary-adrenal as demonstrated by high levels of resting cortisol and corticotropin (ACTH). Schizophrenia is associated with a reduced capacity to excrete water, high rates of polydipsia and hyponatremia, and a greater release of arginine vasopressin [10]. Yet, in a previous study researchers have found that patients with schizophrenia had higher plasma levels of ACTH and cortisol from 13.00 to $14.00 \mathrm{~h}$, a time frame which strongly correlates with a 24-hour period supporting the contention that there is basal overactivity of the pituitary-adrenal in this disorder [10]. It has further been suggested that over time, with the onset of chronic illness, these diminished neurosteroid levels and impaired stress response may be associated with increased sensitivity to brain insult as well as dysregulation of neurotransmission [11]. This in turn is reflected in the deterioration of task-specific behavior including the areas of cognition, emotion and psychosocial functioning. Controversy exists about the use of DHEA-S in the pharmacotherapy of schizophrenia $[11,12]$. Before the development of chlorpromazine, DHEA-S was used in young schizophrenics with modest success in improving deficit symptoms. In particular, DHEA-S, other sex hormones and some of their natural and synthetic derivatives had been used in an attempt to treat deficit symptoms of schizophrenia in both sexes. In addition, a recent report described a possible role for DHEA-S augmentation in the management of negative, depressive, and anxiety symptoms of schizophrenia [13-18].

Although total nitrite levels were also higher in patients, there is no correlation with SAPS total and its subscales and the frequency of hospitalization. According to these results we can speculate that AM has a more significant correlation with the pathophysiological events in schizophrenia than NO. However, there was no correlation between AM and total nitrite levels in the schizophrenics in this study. Additionally, AM levels might be affected in these patients in relation to $\mathrm{NO}$ activity; according to our findings both $\mathrm{NO}$ and $\mathrm{AM}$ may have a pathophysiological role in schizophrenia. The topographical distribution of NOS in the brain may reflect the physiological functions of $\mathrm{NO}$ in the brain. It is hypothesized that $\mathrm{NO}$ is an important neurotransmitter-like modulator which can trigger neurodegenerative processes such as Parkinson's disease, Alzheimer's disease and alcoholism. NO-associated mechanisms are suggested to represent a new avenue for innovative therapeutic strategies for these disorders, thus, it is important to characterize NOS activity, the influence of various pre- and postmortem variables and to establish the regional distribution of NOS activity within the human brain [19-23]. Although there exist a few reports regarding the relationship between the plasma levels of cortisol and NO in schizophrenic patients, the involvement of other adrenal hormones such as AM and DHEA-S in schizophrenic patients remains unknown [23-25].

However, interpretation becomes more difficult because an interference of the pharmacological effects of neuroleptics and the consequences of the clinical improvement of the underlying schizophrenic disorder on neuroendocrine parameters in the course of the treatment period cannot be excluded. Ritsner et al. [26] studied the effects of antipsychotic treatment on hormone secretion in schizophrenic patients. No canonical correlations were observed between changes from baseline through end-of-study in hormonal values and severity of symptoms and emotional distress among responders and nonresponders. In contrast to the findings of Ritsner et al. [26], cortisol levels were significantly affected after 58 weeks of treatment with clozapine compared to baseline conditions [27].

A limitation of our study is the lack of a drug-free schizophrenic control group. Apart from the fact that a 
reliable assessment of endocrine abnormalities under drug-free baseline conditions is not possible, the potential interference of the course of the underlying schizophrenic disorder with the pharmacological effects of neuroleptics complicates the interpretation of hormone changes, which may be relevant in regard to the decline of HPA axis activity.

\section{Conclusion}

The present study suggests that schizophrenic patients differ from control subjects in circulating levels of cortisol, NO and AM. We found no significant differences in DHEA-S levels between schizophrenic and control subjects. In addition, our study indicates that there is a significant positive correlation between cortisol, AM, the duration of disease, and SANS.

\section{References}

$>1$ Ritsner M, Maayan R, Gibel A, Strous RD, Modai I, Weizman A: Elevation of the cortisol/dehydroepiandrosterone ratio in schizophrenia patients. Eur Neuropsychopharmacol 2004; 14:267-273.

$\checkmark 2$ Binello E, Gordon CM: Clinical uses and misuses of dehydroepiandrosterone. Curr Opin Pharmacol 2003;3:635-641.

$>3$ Strous RD, Maayan R, Lapidus R, Goredetsky L, Zeldich E, Kotler M, Weizman A: Increased circulatory dehydroepiandrosterone and dehydroepiandrosterone-sulphate in first-episode schizophrenia: relationship to gender, aggression and symptomatology. Schizophr Res 2004;71:427-434.

4 Shirayama Y, Hashimoto K, Suzuki Y, Higuchi T: Correlation of plasma neurosteroid levels to the severity of negative symptoms in male patients with schizophrenia. Schizophr Res 2002;58:69-74.

$\checkmark 5$ Walsh P, Spelman L, Sharifi N, Thakore JH: Male patients with paranoid schizophrenia have greater ACTH and cortisol secretion in response to metoclopramide-induced AVP release. Psychoneuroendocrinology 2005; 30:431-437.

$\checkmark 6$ Zoroglu SS, Yurekli M, Meram I, Sogut S, Tutkun H, Yetkin O, Sivasli E, Savas HA, Yanik M, Herken H, Akyol O: Pathophysiological role of nitric oxide and adrenomedullin in autism. Cell Biochem Funct 2003;21:5560.

$>7$ Zoroglu SS, Herken H, Yurekli M, Uz E, Tutkun H, Savas HA, Bagci C, Ozen ME, Cengiz B, Cakmak EA, Dogru MI, Akyol O: The possible pathophysiological role of plasma nitric oxide and adrenomedullin in schizophrenia. J Psychiatr Res 2002;36:309-315.

$>8$ Kay SR, Fiszbein A, Opler LA: The positive and negative syndrome scale (PANSS) for schizophrenia. Schizophr Bull 1987;13:261267.

$>9$ Huang CH, Chen ML, Tsai YL, Tsai MT, Chen $\mathrm{CH}$ : Elevated adrenomedullin mRNA in lymphoblastoid cells from schizophrenic patients. Neuroreport 2004;15:1443-1446.
10 Jansen LM, Gispen-de Wied CC, Gademan PJ, De Jonge RC, van der Linden JA, Kahn RS: Blunted cortisol response to a psychosocial stressor in schizophrenia. Schizophr Res 1998;33:87-94.

11 Heuser I, Deuschle M, Luppa P, Schweiger U, Standhardt H, Weber B: Increased diurnal plasma concentrations of dehydroepiandrosterone in depressed patients. J Clin Endocrinol Metab 1998;83:3130-3133.

12 Boudarane M, Legros JJ: Study of the stress response: role of anxiety, cortisol and DHEAS. Encéphale 2002;28:139-146.

13 Akwa Y, Baulieu EE: Dehydroepiandrosterone sulfate and dehydroepiandrosterone: neuroactive neurosteroids. Curr Opin Endocrinol Diabetes 2000;7:160-167.

14 Lerer B, Ran A, Blacker M, Silver H, Weller M, Drummer D, Ebstein B: Neuroendocrine responses in chronic schizophrenia. Schizophr Res 1988;1:405-410.

15 Muck-Seler D, Pivac D, Jakovljevic M, Brzovic Z: Platelet serotonin, plasma cortisol, and dexamethasone supression test in schizophrenic patients. Biol Psychiatry 1999 45:1433-1439.

16 Walder DJ, Walker EF, Lewine RJ: Cognitive functioning, cortisol release, and symptom severity in patients with schizophrenia. Biol Psychiatry 2000;48;1121-1132.

17 Roy A, Pickar D, Doran A, Wolkowitz O, Gallucci W, Chrousos G: The corticotropinreleasing hormone stimulation tests in chronic schizophrenia. Am J Psychiatry 1986;143:1393-1397.

18 Holsboer F: Stress, hypercortisolism and corticosteroid receptors in depression: implications for therapy. J Affect Disord 2001; 62:77-91.
19 Akyol O, Herken H, Uz E, Fadillioglu E, Unal S, Sogut S, Ozyurt H, Savas HA: The indices of endogenous oxidative and antioxidative processes in plasma from schizophrenic patients: the possible role of oxidant/antioxidant imbalance. Prog Neuropsychopharmacol Biol Psychiatry 2002;26:995-1005.

20 Bernstein HG, Stanarius A, Baumann B, Henning H, Krell D, Danos P, Falkai B: Nitric oxide synthase-containing neurons in the human hypothalamus: reduced number of immunoreactive cells in the paraventricular nucleus of depressive patients and schizophrenics. Neuroscience 1998;83:867-875.

21 Dawson VL, Dawson TM: Nitric oxide actions in neurochemistry. Neurochem Int 1996;29:97-111.

22 Herken H, Uz E, Ozyurt H, Akyol O: Red blood cell nitric oxide levels in patients with schizophrenia. Schizophr Res 2001;52:289290.

23 Richards AM, Nichoils MG, Lewis L, LainchBury JG: Adrenomedullin. Clin Sci 1996;91: 3-16.

24 Shan J, Krukoff TL: Distribution of preproadrenomedullin mRNA in the rat central nervous system and its modulation by physiological stressors. J Comp Neurol 2001;26: 88-100.

25 Henning U, Krieger K, Loeffler S, Rivas F, Orozco G, Manuel G: Increased levels of glucocorticoid receptors and enhanced glucocorticoid receptor auto-regulation after hydrocortisonechallengein B-lymphoblastoids from patients with affective disorders. Psychoneuroendocrinology 2005;30:325-332.

26 Ritsner M, Gibel M, Maayan A, Ratner Y, Ram E, Biadsy H, Modai I, Weizman A: Cortisol/dehydroepiandrosterone ratio and responses to antipsychotic treatment in schizophrenia. Neuropsychopharmacology 2005; 30:1913-1922.

-27 Mann K, Rossbach W, Muller MJ, MullerSiecheneder F, Pott T, Linde I: Nocturnal hormone profiles in patients with schizophrenia treated with olanzapine. Psychoneuroendocrinology 2006;31:256-264. 